\title{
Prognostic factors in traumatic brain injury and their association with outcome
}

\author{
Bartłomiej Kulesza', Adam Nogalski', Tomasz Kulesza', Andrzej Prystupa² \\ ${ }^{1}$ Department of Trauma Surgery and Emergency Medicine, Medical University of Lublin, Poland \\ ${ }^{2}$ Department of Internal Medicine, Medical University of Lublin, Poland
}

Kulesza B, Nogalski A, Kulesza T, Prystupa A. Prognostic factors in traumatic brain injury and their association with outcome. J Pre-Clin Clin Res. 2015; 9(2): 163-166. doi: 10.5604/18982395.1186499

\begin{abstract}
Introduction. Traumatic brain injuries (TBI) are a real social problem, with an upward trend worldwide. TBI is the leading cause of death and disability, especially among young men. Each year in Europe, and also in Poland, 243 per 100,000 individuals suffer from TBI. Assessing prognosis after traumatic brain injury is very important in order to help clinicians to make a decision about the implementation of specific methods of treatment, and to make communication with the patient and the patient's family easier.

Objective. The objective of this review was to present prognostic factors, to assess outcomes within a short time after a moderate to severe traumatic brain injury, as well as to predict functional outcome. The most important independent variables were: age, Glasgow Coma Scale (GCS) motor score, pupil response, Marshall CT classification and traumatic subarachnoid haemorrhage. Other important prognostic factors included hypotension, hypoxia, glucose, coagulopathy, haemoglobin and category of CT characteristic, such as midline shift, mass lesion, basal cistern.

Conclusions. Gender and intraventricular haemorrhage did not have predictive value. This subject needs much more research in the area of new prognostic factors which would be better associated with outcome after traumatic brain injury.
\end{abstract}

I Key words

traumatic brain injury, prognostic factors, outcome, prognosis

\section{INTRODUCTION}

It has been observed that a growing number of injuries are associated with industrialization and the rapid growth of motorization. Traumatic brain injuries (TBI) are a real social problem, with an upward trend worldwide [1]. Two million individuals each year sustain traumatic brain injury in the United States, resulting in 56,000 deaths [2]. The incidence rate in Europe is approximately 243 per 100,000 per year [3]. This type of injury is the cause of $2 / 3$ of all deaths after injuries, especially among young men. Presumably, the epidemiological situation in Poland is similar to other European countries [1,3].

TBI is a complex injury caused by a sudden trauma to the brain or by an object piercing the brain tissue in which a broad spectrum of symptoms and disabilities can be observed [4]. It is a major cause of death and disability. Establishing a reliable prognosis after injury is difficult, as is captured in the Hippocratic aphorism, 'No head injury is too severe to despair of, nor too trivial to ignore' [5]. On the other hand, clinicians treating patients often make therapeutic decisions based on their assessment of prognosis. $80 \%$ of doctors believe that an accurate assessment of prognosis was important when making decisions about the use of specific methods of treatment, such as hyperventilation, barbiturates, or mannitol. Assessment of prognosis could help communication with a patient and the family [6].

Address for correspondence: Andrzej Prystupa, Department of Internal Medicine, Medical University of Lublin

E-mail: aprystup@mp.pl

Received: 12 November 2014; accepted: 27 November 2015

\section{OBJECTIVE}

The aim of this study was to present current knowledge about prognostic value of determinant in TBI and the association between determinant and outcomes. The Glasgow Outcome Scale (GOS) was used in most studies at 6 months postinjury in order to assess the outcome. The scale was divided into: favourable (level 4 or 5) or unfavourable (level 1, 2 or 3) (Tab. 1). Severe traumatic brain injuries were categorised according to the Glasgow Coma Scale (GCS) on mild TBI (13-15 GCS), moderate TBI (9-12 GCS) and severe TBI (3-8 GCS). Most studies consider patients of moderate and/or severe TBI (3-12 GCS).

Table 1. Glasgow Outcome Scale

\begin{tabular}{ll}
\hline Level & Term \\
\hline 1 & Dead \\
\hline 2 & Persistent vegetative state \\
\hline 3 & Severe disability \\
\hline 4 & Moderate disability \\
\hline 5 & Good recovery \\
\hline
\end{tabular}

\section{DISCUSSION}

Prognostic factors are divided into 7 categories, all of them associated with outcomes but with strong evidence for predicting outcomes at 6 months: Glasgow Coma Scale (GCS) admission, motor score, mid-line shift on computer tomography scan, subdural haematoma. Gender and intraventricular haemorrhage did not have predictive value [7]. 
Gender. Trauma and TBI are more common in males than females. There was no evidence of relationship between gender and outcomes $[7,8,9,10,11]$. There are a few studies which indicate that gender was associated with different outcomes, but those studies included a smaller number of patients after TBI. It has been shown that the better outcomes in females might be due to the neuroprotective effect of progesterone [12]. On the other hand, several other studies indicate that females have poorer prognosis than males $[13,14]$.

Age. Increasing age was associated with worse outcomes $[7,8$, $9,15]$. Other authors state that the association was apparent only after the age of $40[6,16]$, and especially above 60 [17]. On the other hand, there is no association between TBI outcome and age lower than 40 years $[6,17]$. Plausible explanations for this include extracranial comorbidities, change in brain plasticity, or differences in clinical management associated with increasing age [6]. Some studies found no relationship between age and outcomes $[10,18]$, or inverse relationship, an older age was associated with a better outcome [11].

Glasgow Coma Scale (GCS). According to the literature, there is strong evidence for the prognostic value of the GCS on admission to hospital and the GCS motor score $[7,8,15$, $17,19]$. Lower admission GCS and lower GCS motor scores were associated with worse outcomes $[7,15,19,20]$. The GCS showed a clear linear relation with morality [6].

Pupillary reaction. There was relation between absence of or abnormal pupillary reactions and worse outcomes in TBI $[8,15,19]$. Pupil abnormalities were noted more frequently in patients with mass lesions, compressed cisterns, shift, and in patients with CT class III/IV than in patients with CT class I/II [21].

Computer Tomography (CT) scan characteristics. Computerized tomography (CT) scanning provides an objective assessment of structural damage to the brain and associated outcome following traumatic brain injury. The CT classification and individual CT characteristic is associated with outcome. The most common classification used after TBI was the Marshall classification, proposed in 1991 by Marshall et al. (Tab. 2) [21]. CT classifications III and IV were especially related to morality, while CT classifications I or II were more frequent associated with a favourable outcome [21]. Strong evidence was found for the separate category mid-line shift $[8,21,22,23]$ and increasing size of

Table 2. Marshall computerized tomography (CT) classification.

\begin{tabular}{ll}
\hline Category & Definition \\
\hline $\begin{array}{l}\text { Diffuse injury I (no } \\
\text { visible pathology) }\end{array}$ & No visible intracranial pathology seen on CT scan. \\
\hline Diffuse injury II & $\begin{array}{l}\text { Cisterns are present with mid-line shift 0-5 mm and/or } \\
\text { lesion densities present; no high or mixed density lesion } \\
>25 \text { cc may include bone fragments and foreign bodies. }\end{array}$ \\
\hline $\begin{array}{ll}\text { Diffuse injury III } \\
\text { (swelling) }\end{array}$ & $\begin{array}{l}\text { Cisterns compressed or absent with mid-line shift } \\
0-5 \text { mm; no high or mixed density lesion }>25 \text { mm. }\end{array}$ \\
\hline Diffuse injury IV (shift) & $\begin{array}{l}\text { Mid-line shift }>5 \text { mm; no high or mixed density lesion } \\
>25 ~ c c ~\end{array}$ \\
\hline Evacuated mass lesion & Any lesion surgically evacuated. \\
\hline - mass lesion & $\begin{array}{l}\text { High or mixed density lesion }>25 \text { cc; not surgically } \\
\text { evacuated }\end{array}$ \\
\hline
\end{tabular}

the shift associated with poorer outcome [21]. The prognosis in patients with mass lesions was better for patients with an epidural haematoma, and poorer for an acute subdural haematoma [21, 24]. Evidence for the prognostic value of subdural haematoma was strong $[8,21]$. Presence of traumatic subarachnoid haemorrhage, obliteration of the basal cistern or third ventricle, and non-evacuated haematoma were associated with poorer outcome at 6 months $[6,8,21,25$, 26]. There was strong evidence of no relationship between intraventricular haemorrhage and outcome [7, 20, 27].

Vital signs. Vital signs are used to measure the body's basic functions. TBI causes dysautonomia manifested by episodes of fluctuations in blood pressure (BP), pulse rate (PR), respiratory rate $(\mathrm{RR})$, temperature, muscle tone, decorticate or decerebrate posturing, and profuse sweating. Dysautonomia occurs in $10 \%$ of patients surviving severe TBI who tended to have poorer outcomes $[17,28]$. Most of these parameters were evaluated one-half hour (one and a half hours or half an hour) after the patient's arrival in the emergency room. Hypotension and hypoxia following TBI is recognized as a significant secondary insult associated with adverse outcome $[17,29,30]$. There is a characteristic U-shaped relationship between systolic blood pressure (SBP) and TBI outcome. The best outcomes were observed for values of SBP between 135 - $90 \mathrm{mmHg}$. Values of SBP higher than 135 or lower than $90 \mathrm{mmHg}$ were associated with poorer outcomes. Current guidelines for the management of blood pressure in TBI focus on the prevention of SBP $<90 \mathrm{mmHg}$ (hypotension) [17, 31]. Diastolic blood pressure (DBP) of less than $50 \mathrm{mmHg}$ was associated with higher morality [17]. Hypoxia and oxygen saturation lower than $90 \%$ was associated with poor outcome [32]. Both increase and decrease in RR beyond normal range is associated with a poor outcome in TBI. There are similar findings about the association between PR and morality in patients with TBI [17].

Laboratory parameters. This study describes the predictive value of various laboratory parameters routinely recorded on admission following TBI. Hyperglycaemia is a cause of secondary damage in patients after TBI, and is associated with poorer outcome [33]. Coagulopathy is a major determinant of disability and death in patients with traumatic intracranial haemorrhage. Coagulopathy, especially prothrombin time and platelets, is associated with the outcome in patients after TBI $[33,34]$. Glucose and prothrombin time showed a positive linear relationship with outcome (increasing values associated with poorer outcome) [33]. Anaemia is a common problem in critically ill patients and it is associated with poorer outcome in TBI [33]. Haemoglobin, platelets, and pH showed an inverse linear to outcome (low values associated with poorer outcome) [33]. Both hypo- and hypernatraemia are associated with poorer outcome, but hyponatraemia is a relatively infrequent occurrence on admission following TBI. Sodium demonstrated a U-shaped relationship with outcome, but hyponatraemia is more strongly related to poorer outcome [33]. There is a weak relationship between hypernatraemia and outcome, which was primarily related to mortality [33].

TBI prognosis calculators. In the Internet there were two TBI Prognosis calculators available, which are based on prognostic models that combine data from patients involved 
in clinical trials to predict clinical outcome, but they should be used with caution [35]. The first of them could help in estimating mortality at 14 days, as well as death and severe disability at 6 months, and include the basic model, and also CT model [6] (Fig. 1). The second could help estimate the 6 -month outcome and includes 3 models of increasing complexity [36] (Fig. 2).

\section{Head injury prognosis CRAS}

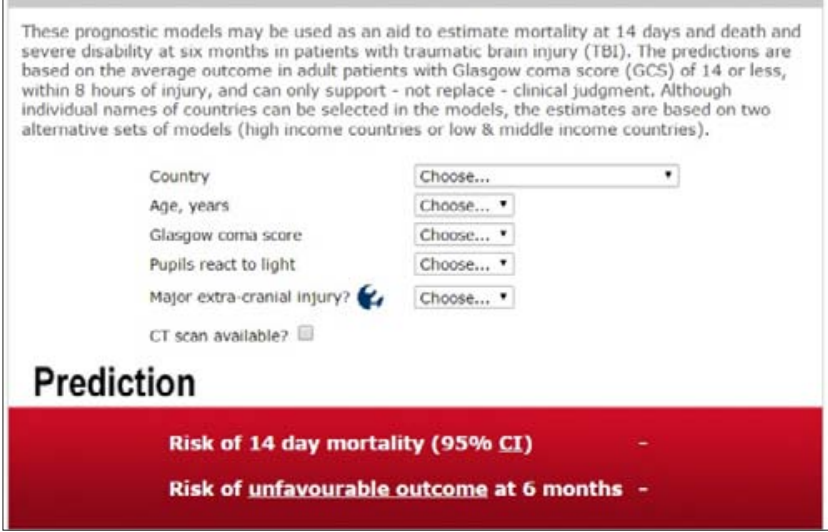

Figure 1. Screenshot of web TBI calculator.

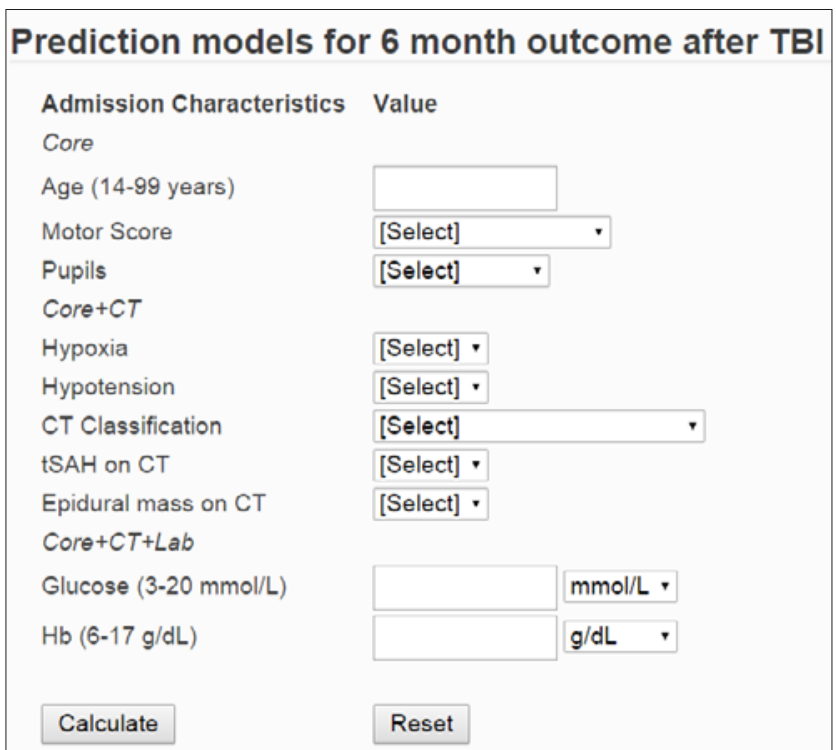

Figure 2. Screenshot of web TBI calculator available.

(http://www.crash.Ishtm.ac.uk/and at: http://www.tbi-impact.org/?p=impact/calc). The screenshots were authorized by the originators

\section{CONCLUSION}

Assessing prognosis after traumatic brain injury was both very important and difficult. There were a lot of different prognostic factors related to outcome that could help. The most powerful independent variables were: age, Glasgow Coma Scale motor score, pupil response, Marshall CT classification and traumatic subarachnoid haemorrhage [8]. Other important prognostic factors included: hypotension, hypoxia, glucose, coagulopathy, haemoglobin and category of CT characteristic, such as mid-line shift, mass lesion and basal cistern $[8,21]$. Gender and intraventricular haemorrhage did not have predictive value [7]. In the Internet there were 2 TBI Prognosis calculators available which could help to assess outcome, but should be used with caution. This subject requires a lot of research in new prognostic factors which would be better associated with outcome after traumatic brain injury.

\section{REFERENCES}

1.Pilśniak J, Ślusarz R. Epidemiologia urazów czaszkowo-mózgowych w materiale własnym Pogotowia Ratunkowego w Rypinie: Badania retrospektywne. Pielęgniarstwo Neurologiczne i Neurochirurgiczne 2013; 2(1): 4-8 (in Polish).

2. Salim A, Ley EJ, Cryer HG, Margulies DR, Ramicone E, Tillou A. Positive serum ethanol level and mortality in moderate to severe traumatic brain injury. Arch Surg. 2009; 144(9): 865-871.

3. Tagliaferri F, Compagnone C, Korsic M, Servadei F, Kraus J. A systematic review of brain injury epidemiology in Europe. Acta Neurochir. 2006; 148(3): 255-268.

4. Thurman DJ, Alverson C, Dunn KA, Guerrero J, Sniezek JE. Traumatic brain injury in the United States: A public health perspective. J Head Trauma Rehabil. 1999; 14(6): 602-615.

5. Hukkelhoven CW, Steyerberg EW, Habbema JD, Farace E, Marmarou A, Murray GD, et al.. Predicting Outcome after Traumatic Brain Injury: Development and International Validation of Prognostic Scores Based on Admission Characteristics. J Neurotrauma. 2005; 22(10): 1025-1039.

6. MRC CRASH Trial Collaborators, Perel P, Arango M, Clayton T, Edwards P, Komolafe E, at al. Predicting outcome after traumatic brain injury: practical prognostic models based on large cohort of international patients. BMJ. 2008; 336(7641): 425-429.

7. Husson EC, Ribbers GM, Willemse-van Son AH, Verhagen AP, Stam HJ. Prognosis of six-month functioning after moderate to severe traumatic brain injury: a systematic review of prospective cohort studies. J Rehabil Med. 2010; 42(5): 425-436.

8. Murray GD, Butcher I, McHugh GS, Lu J, Mushkudiani NA, Maas AI, et al. Multivariable prognostic analysis in traumatic brain injury: results from the IMPACT study. J Neurotrauma 2007; 24(2): 329-337.

9. Mushkudiani NA, Engel DC, Steyerberg EW, Butcher I, Lu J, Marmarou A, et al. Prognostic value of demographic characteristics in traumatic brain injury: results from the IMPACT study. J Neurotrauma 2007; 24(2): 259-269.

10. Fabbri A, Servadei F, Marchesini G, Stein SC, Vandelli A. Early predictors of unfavourable outcome in subjects with moderate head injury in the emergency department. J Neurol Neurosurg Psychiatr. 2008; 79(5): 567-573.

11. Shutter L, Tong KA, Holshouser BA. Proton MRS in acute traumatic brain injury: role for glutamate/glutamine and choline for outcome prediction. J Neurotrauma. 2004; 21(12): 1693-1705.

12. Groswasser Z, Cohen M, Keren O. Female TBI patients recover better than males. Brain Inj. 1998; 12(9): 805-808.

13. Ponsford JL, Myles PS, Cooper DJ, Mcdermott FT, Murray LJ, Laidlaw $\mathrm{J}$, et al. Gender differences in outcome in patients with hypotension and severe traumatic brain injury. Injury. 2008; 39(1): 67-76.

14. Moppett IK. Traumatic brain injury: assessment, resuscitation and early management. Br J Anaesth. 2007; 99(1): 18-31.

15. Hebb MO, McArthur DL, Alger J, Etchepare M, Glenn TC, Bergsneider $\mathrm{M}$, et al. Impaired percent alpha variability on continuous electroencephalography is associated with thalamic injury and predicts poor long-term outcome after human traumatic brain injury. J Neurotrauma 2007; 24(4): 579-590.

16. Hukkelhoven CW, Steyerberg EW, Rampen AJ, Farace E, Habbema JD, Marshall LF, et al. Patient age and outcome following severe traumatic brain injury: an analysis of 5600 patients. J Neurosurg. 2003; 99(4): $666-73$.

17. Saadat S, Akbari H, Khorramirouz R, Mofid R, Rahimi-Movaghar V. Determinants of mortality in patients with traumatic brain injury. Ulus Travma Acil Cerrahi Derg. 2012; 18(3): 219-224

18. Wang JY, Bakhadirov K, Devous MD Sr, Abdi H, McColl R, Moore C, et al. Diffusion tensor tractography of traumatic diffuse axonal injury. Arch Neurol. 2008; 65(5): 619-626.

19. Marmarou A, Lu J, Butcher I, McHugh GS, Murray GD, Steyerberg EW, et al. Prognostic value of the Glasgow Coma Scale and pupil reactivity in traumatic brain injury assessed pre-hospital and on enrollment: an IMPACT analysis. J Neurotrauma. 2007; 24(2): 270-280. 
20. Fabbri A, Servadei F, Marchesini G, Stein SC, Vandelli A. Early predictors of unfavourable outcome in subjects with moderate head injury in the emergency department. J Neurol Neurosurg Psychiatr 2008; 79(5): 567-573.

21. Maas AI, Steyerberg EW, Butcher I, Dammers R, Lu J, Marmarou A, et al. Prognostic Value of Computerized Tomography Scan Characteristics in Traumatic Brain Injury: Results from the IMPACT Study. J Neurotrauma. 2007; 24(2): 303-314.

22. Hiler M, Czosnyka M, Hutchinson P, Balestreri M, Smielewski P, Matta $\mathrm{B}$, et al. Predictive value of initial computerized tomography scan, intracranial pressure, and state of autoregulation in patients with traumatic brain injury. J Neurosurg. 2006; 104(5): 731-737.

23. Pillai SV, Kolluri VR, Praharaj SS. Outcome prediction model for severe diffuse brain injuries: development and evaluation. Neurol India. 2003; 51(3): 345-349.

24. Bahloul M, Chelly H, Ben Hmida M, Ben Hamida C, Ksibi H, Kallel H, et al. Prognosis of traumatic head injury in South Tunisia: a multivariate analysis of 437 cases. J Trauma. 2004; 57(2): 255-261.

25. Servadei F, Nasi MT, Giuliani G, Cremonini AM, Cenni P, Zappi D, et al. CT prognostic factors in acute subdural haematomas: the value of the "worst" CT scan. Br J Neurosurg. 2000; 14(2): 110-116.

26. Mattioli C, Beretta L, Gerevini S, Veglia F, Citerio G, Cormio M, et al. Traumatic subarachnoid hemorrhage on the computerized tomography scan obtained at admission: a multicenter assessment of the accuracy of diagnosis and the potential impact on patient outcome. J Neurosurg. 2003; 98(1): 37-42.

27. Lannoo E, Van Rietvelde F, Colardyn F, Lemmerling M, Vandekerckhove $\mathrm{T}$, Jannes $\mathrm{C}$ et al. Early predictors of mortality and morbidity after severe closed head injury. J Neurotrauma. 2000; 17(5): 403-414.
28. Hendricks HT, Heeren AH, Vos PE. Dysautonomia after severe traumatic brain injury. Eur J Neurol. 2010; 17(9): 1172-1177.

29. Rejeb I, Chakroun O, Chtara K, Boujelbene M, Ksibi H, Chaari A, et al. Factors predicting early outcome in patients admitted at emergency department with severe head trauma. J Acute Dis. 2015; 4(1): 68-72.

30. McHugh GS, Engel DC, Butcher I, Steyerberg EW, Lu J, Mushkudiani $\mathrm{N}$, et al. Prognostic value of secondary insults in traumatic brain injury: results from the IMPACT study. J Neurotrauma. 2007; 24(2): 287-293.

31. Butcher I, Maas AI, Lu J, Marmarou A, Murray GD, Mushkudiani NA, et al. Prognostic value of admission blood pressure in traumatic brain injury: results from the IMPACT study. J Neurotrauma. 2007; 24(2): 294-302

32. Hukkelhoven CW, Steyerberg EW, Farace E, Habbema JD, Marshall LF, Maas AI. Regional differences in patient characteristics, case management, and outcomes in traumatic brain injury: experience from the tirilazad trials. J Neurosurg. 2002; 97(3): 549-557.

33. Van Beek JG, Mushkudiani NA, Steyerberg EW, Butcher I, McHugh GS, Lu J, et al. Prognostic value of admission laboratory parameters in traumatic brain injury: results from the IMPACT study. J Neurotrauma. 2007; 24(2): 315-328.

34. Joseph B, Aziz H, Zangbar B, Kulvatunyou N, Pandit V, O'Keeffe T, et al. Acquired coagulopathy of traumatic brain injury defined by routine laboratory tests: Which laboratory values matter?. J Trauma Acute Care Surg. 2014; 76(1): 121-125.

35. Traumatic Brain Injury (TBI) Prognosis http://ifeinthefastlane.com/ ccc/traumatic-brain-injury-tbi-prognosis/

36. Steyerberg EW, Mushkudiani N, Perel P, Butcher I, Lu J, McHugh GS, et al. Predicting outcome after traumatic brain injury: development and international validation of prognostic scores based on admission characteristics. PLoS Med. 2008; 5(8): e165; discussion e165. 